\title{
SENTIMIENTOS RELIGIOSOS Y MORAL EN LOS CONCEPTOS POLÍTICOS DEL PRIMER LIBERALISMO ESPAÑOL
}

ANA ISABEL GONZÁLEZ MANSO 
SUMARIO

1. INTRODUCCIÓN. 2. MORAL Y RELIGIÓN. 3. DEBATES PARLAMENTARIOS Y PERIODÍSTICOS. 4. CONSECUENCIAS EN EL SIGNIFICADO DE LOS TÉRMINOS POLÍTICOS. 5. CONCLUSIÓN. 


\title{
SENTIMIENTOS RELIGIOSOS Y MORAL EN LOS CONCEPTOS POLÍTICOS DEL PRIMER LIBERALISMO ESPAÑOL
}

\author{
POR \\ ANA ISABEL GONZÁLEZ MANSO \\ Departamento de Derecho Constitucional \\ e Historia del Pensamiento \\ Universidad del País Vasco
}

\section{INTRODUCCIÓN}

«En la España del siglo XVIII todo español acepta la fe católica» ${ }^{1}$. El carácter católico de la sociedad española de finales del siglo XVIII inicios del siglo XIX, que J. A. Maravall llega a denominar de Catolicismo liberal ${ }^{2}$, es un hecho

${ }^{1}$ LA PARRA LÓPEZ, E. (1985). El primer liberalismo español y la Iglesia. Las Cortes de Cádiz, Alicante, Instituto de Estudios Juan Gil-Albert, 9. Este autor es contundente al negar que los diputados gaditanos tanto en su actitud personal como en las decisiones reformistas tomadas, pretendieran destruir la Iglesia católica. Tenían una concepción religiosa de la sociedad (261) queriendo cambiar solo la organización eclesiástica.

${ }^{2}$ J. A. MARAVALL define este catolicismo liberal como el intento de «fundir con un cuerpo de creencias heredadas del pasado, las novedades introducidas por el pensamiento revolucionario» (MARAVALL, J. A. (1972). «Sobre orígenes y sentido del catolicismo liberal en España» en Homenaje a Aranguren, Madrid, Revista de Occidente, 229-266, 229). El católico liberal español trata de ligar liberalismo y catolicismo, lo cual le diferencia del liberal católico europeo que trata de defender la libertad confesional del católico frente al mundo no católico (248). 
destacado por todos los autores. Pero al mismo tiempo, y haciéndose eco de las reflexiones de los propios protagonistas del debate gaditano, se ha tendido a considerar a los publicistas españoles de la primera mitad del siglo XIX, volátiles en sus ideas políticas así como en sus sentimientos religiosos ${ }^{3}$. Esta última crítica en particular está muy presente en los debates parlamentarios durante la redacción de la Constitución gaditana, siendo utilizada como arma arrojadiza cada vez que se produce un debate relacionado con la Iglesia. El articulado de la Constitución de Cádiz ha sido analizado inquisitivamente intentando descubrir tanto las verdaderas intenciones políticas como religiosas de sus redactores. En particular el artículo 12, donde se vinculan Nación y Catolicismo, ha dado lugar a toda una controversia sobre si sus redactores buscaron intencionadamente la ambigüedad para permitir diferentes interpretaciones o si fue en realidad una concesión al mundo más tradicional ${ }^{4}$. Díez del Corral, en su explicación de los orígenes del posterior doctrinarismo español, considera que los liberales no dejaron de tener, a pesar de la secularización, «la vista (...) centrada en el problema radical de la salvación» ${ }^{5}$. Los estudios de Fernández Albaladejo ${ }^{6}$ así como los realizados por

${ }^{3}$ Sin pretender hacer una enumeración exhaustiva, son numerosos los estudios que se han centrado en intentar explicar las aparentes contradicciones observadas en los publicistas. Así tenemos entre otros a VARELA SUANZES-CARPEGNA, J. (1983). Tradición y liberalismo en Martínez Marina, Oviedo, Fac. de Derecho; DÍEZ DEL CORRAL, L. (1984). El liberalismo doctrinario, Madrid, Centro de Estudios Constitucionales; MARTÍNEZ TORRÓN, D. (1993). Ideología y literatura en Alberto Lista, Sevilla, Alfar; FERNÁNDEZ ALBALADEJO, P. (1996). «Observaciones políticas: algunas consideraciones sobre el lenguaje político de Francisco Martínez Marina» en IGLESIA FERREIRÓS A., editor, Estat, Dret, Societat al segle XVIII, Homenaje al Prof. Josep M. Gay i Escoda, Barcelona, Asociación catalana d'História del Dret «Jaume de Montjuic»; PORTILLO VALDÉS, J. M. (2000). Revolución de nación. Orígenes de la cultura constitucional en España, 1780-1812, Madrid, Centro de Estudios Políticos y Constitucionales. Si el pensamiento de estos publicistas se analiza desde la perspectiva constitucional-política efectivamente puede dar la sensación de un cambio, en algunos casos radical, de postura ideológica. Pero posiblemente sea necesario para llevar a cabo este análisis incorporar otra variable más que condiciona totalmente las conclusiones a las que se llega, y ésta es el componente religioso-católico.

${ }^{4}$ Así lo destaca J. M. PORTILLO VALDÉS relacionándolo con el repudio, bastantes años después, de este artículo por parte de algunos de sus autores; recuérdese Agustín de Argüelles en su Examen bistórico de la reforma constitucional (1835) o el conde de Toreno (PORTILLO VALDÉS, J. M. (2007). «De la monarquía católica a la nación de los católicos». Historia y Política, enero-julio, 17-35, 25). Desde el punto de vista conservador, Fr. R. DE VÉLEZ interpreta este artículo como «el pretexto autorizado por la Constitución, para ingerirse las Cortes en la reforma de la Iglesia» y llevarla a su destrucción siguiendo principios jansenistas (DE VÉLEZ, R. Fr. (1818). Apología del altar y del trono o Historia de las reformas hechas en España en tiempo de las Ilamadas Cortes, e impugnación de algunas doctrinas publicadas en la Constitución, diarios y otros escritos contra la religión y el Estado, T. I, Madrid, imprenta de Cano, 208 y capítulo XVIII).

5 DÍEZ DEL CORRAL, L. (1984). El liberalismo, 484. 
Portillo Valdés ${ }^{7}$ han buscado relacionar y hacer compatibles los posicionamientos escolásticos de publicistas como Francisco Martínez Marina ${ }^{8}$ o Joaquín Lorenzo Villanueva ${ }^{9}$, con las nuevas doctrinas políticas defendidas y en particular,

${ }^{6}$ FERNÁNDEZ ALBALADEJO, P. (1996). «Observaciones», 691-714. Este artículo centrado principalmente, que no exclusivamente, en la obra de Martínez Marina Teoría de las Cortes, aboga por definir esta simbiosis como de cristianismo cívico (712).

7 PORTILLO VALDÉS, J. M. (2000). Revolución, en particular 259-491. El autor distingue claramente dos posiciones en torno a como la religión condiciona el significado de soberanía, nación o libertad, en función de la interpretación de la noción de obligación (320-321).

${ }^{8}$ Hay numerosos estudios centrados en la figura de este autor que como sucede con otros publicistas es difícil de encuadrar ideológicamente: así tenemos el realizado por POSADA A., que lo califica de espíritu liberal haciendo compatible su amor por la libertad moral y política con los dogmas (POSADA, A. (1933). «Estudio Preliminar» en MARTÍNEZ MARINA, F. Principios naturales de la moral, de la política y de la legislación [1823-1824], Madrid, Academia de Ciencias Morales y Políticas, V-XXXIX, XXXVII), el realizado por J. A. MARAVALL donde partiendo de una calificación de ilustrado, de individualista, observa los intentos realizados por Marina para hacer compatible un origen natural de la sociedad con su desarrollo histórico y político pero desde una posición fundamentalmente tradicionalista ((MARAVALL, J. A. (1957). «Estudio Prelimar» en MARTÍNEZ MARINA, F. Discurso sobre el origen de la monarquía y sobre la naturaleza del gobierno español [1813], Madrid, Centro de Estudios Constitucionales, 7-78, 50 y 66), o el realizado por VARELA SUANZES-CARPEGNA, J. (1983): Tradición, 60, 86, que considera que este autor presenta dificultades para entender los nuevos conceptos políticos.

9 Lo mismo ocurre con este autor; así tenemos el trabajo de MARAVALL, «Sobre orígenes», 233, donde además de considerar a Villanueva el primer representante del llamado catolicismo liberal, valora la unión que realiza este autor entre liberalismo y catolicismo en el plano religioso al igual que empieza a vislumbrar una alianza semejante en el terreno político. Sin entrar en el debate entre la diferente postura manifestada por Villanueva (que de un punto de vista político se podría calificar de absolutista) en el Catecismo o en su polémica con el obispo Grégoire, frente a la que presenta en Cádiz durante la redacción de la Constitución o en Las angélicas fuentes (más típica del mundo liberal), Villanueva ha sido considerado como el principal representante del «jansenismo español» (rigorismo, regalismo, defensa de la Iglesia hispana primitiva, episcopalismo). Desde un punto de vista político, J. VARELA SUANZES-CARPEGNA, lo sitúa en el bando realista (o más específicamente liberal del Antiguo Régimen) pero con afán reformista (VARELA SUANZES-CARPEGNA, J. (1983). La teoría del Estado en los orígenes del constitucionalismo hispánico. Las Cortes de Cádiz, Madrid, Centro de Estudios Constitucionales, 19-20; PORTILLO, Revolución de nación, 333 destaca su afán de divulgar cómo los católicos podían entender la soberanía nacional; E. LA PARRA LÓPEZ lo define como un defensor de la «ilustrada piedad» y del catolicismo y así pues sin un verdadero afán de reformismo político (LA PARRA LÓPEZ, E. (2008).»Joaquín L. Villanueva en el debate sobre la Inquisición de las Cortes de Cádiz» en RAMÍREZ ALERÓN G., editor, Valencianos en Cádiz. Joaquín Lorenzo Villanueva y el grupo valenciano en las Cortes de Cádiz, Cádiz, Biblioteca de las Cortes de Cádiz, 287-302, 302); G. RAMÍREZ ALEDÓN valora más su aportación política que centra en el regalismo y que le conduce a realizar un trasvase de rey a nación (RAMÍREZ ALEDÓN, G. (2008). «Villanueva, diputado y polemista en Cádiz» en RAMÍREZ ALERÓN G., editor, Valencianos en Cádiz. Joaquín Lorenzo Villanueva y el grupo valenciano en las Cortes de Cádiz, Cádiz, Biblioteca de las Cortes de Cádiz, 217-285, 263).

(C) UNED. Revista de Derecho Político

N. ${ }^{82}$, septiembre-diciembre 2011, págs. 431-456 
con el carácter liberal de la Constitución gaditana. Así mismo Fernández Sebastián explica cómo fue posible conciliar libertad de expresión y otras libertades defendidas en la Constitución con la intolerancia religiosa presente en la mis$\mathrm{ma}^{10}$. Posiblemente en el fondo suponga el relativizar la importancia de la intolerancia religiosa, justificada por el contexto cultural del momento, frente a la gran aportación que supuso el intento de conciliar elementos del derecho natural, de la moral y de la religión con los nuevos conceptos políticos.

No pueden ser eludidas (aunque frecuentemente se ha hecho por representar una realidad incomoda de explicar) las continuas alusiones en los debates gaditanos, por parte de los representantes de cualquier tendencia ideológica, a la virtud, a la moral, a los derechos naturales; en el caso de los liberales vinculándolos con los nuevos conceptos políticos o los nuevos significados de los mismos ${ }^{11}$, en el caso de los tradicionales, vinculándolos con los antiguos significados ${ }^{12}$. Los mismos liberales protagonistas de los debates gaditanos son frecuentemente conscientes de que están creando una amalgama de principios, característica del proceso español (y extensible al resto del mundo hispano), donde se hace conciliar, marcando diferencias, el neoescolasticismo heredado ${ }^{13}$ y muy presente en sus consciencias por adaptarse bien a sus creencias religiosas, con los principios defendidos por Locke, Montesquieu o Rousseau ${ }^{14}$. La historiografía española, en su mayoría, ha buscado

${ }^{10}$ FERNÁNDEZ SEBASTIÁN, J. (2011). «The question of freedom of expresion and toleration in the hispanic world between enlightenment and liberalism». Past and Present (pendiente de publicación).

${ }^{11}$ PORTILLO, Revolución de nación, 327. El autor destaca la diferente interpretación constitucional que van a dar liberales y moderados partiendo de unos mismos principios católicos.

12 Aunque ha sido frecuente considerar la Religión asociada a una alegoría absolutista y la Libertad o la Justicia a una liberal, C. REYERO destaca las frecuentes referencias bíblicas en los discursos liberales o el papel de la Religión en las fiestas constitucionales (REYERO, C. (2010). Alegoría, nación y libertad. El olimpo constitucional de 1812, Madrid, Siglo XXI, 130-133).

13 VARELA SUANZES-CARPEGNA, limita solamente a Muñoz Torrero y a Oliveros la influencia del iusnaturalismo tradicional, católico, escolástico y el tratamiento constitucional de la religión, valorado como antiliberal, como fruto de una concesión a las circunstancias históricas (VARELA SUANZES-CARPEGNA, J. (2007). Política y Constitución en España (1808-1978), Madrid, Centro de Estudios Políticos y Constitucionales, 64-66).

14 Sin embargo el pensamiento de autores como F. Martínez Marina o A. Lista ha sido valorado como reticente al cambio y a la adaptación a los nuevos conceptos políticos: en particular VARELA, Tradición; 109-111; JURETSCHKE, H. (1951). Vida, obra y pensamiento de Alberto Lista, Madrid, CSIC. Mencionamos en particular a A. Lista, autor tradicionalmente considerado paradigma de volatilidad política e incluso de insinceridad religiosa que en el trabajo A. I. GONZÁLEZ MANSO, pretendemos mostrar como anticipó muchas de las características del liberalismo moderado (en una línea interpretativa diferente de la de Martínez Marina) y que será la que termine por imponerse, todo ello marcado, eso sí, por un papel rector de la moral y de la religión en la or- 
más destacar las similitudes de los principios defendidos en la Constitución gaditana con las ideas circulantes en Europa de soberanía, nación...(similitudes que evidentemente existen), relegando a explicaciones marginales (o a reminiscencias de pensamiento tradicional) la influencia de ciertos principios religiosos y de moral en el significado atribuido por los publicistas a los conceptos políticos.

El presente artículo pretende, en la línea abierta por Fernández Albaladejo y Portillo Valdés, destacar en los discursos parlamentarios y en los periodísticos las referencias a la virtud, a la moral, a los derechos naturales y cómo esta defensa de los mismos condicionó el significado atribuido por los políticos a los conceptos manejados ${ }^{15}$. Sin querer marcar un particularismo hispano, pretendemos reivindicar la creación, por parte del mundo liberal, de un pensamiento más complejo, elaborado y sobre todo coherente en el tiempo, de lo que se ha considerado hasta ahora, donde las creencias religiosas juegan un papel estructural y, así pues, fundamental para entender el significado de los conceptos manejados. Es decir se hace necesario analizar un campo semántico amplio que englobe política y religión. Tal y como indica J. Varela Suanzes-Carpegna ${ }^{16}$, la historia constitucional requiere la utilización de dos enfoques complementarios uno de tipo normativo-institucional y otro de tipo doctrinal. En este trabajo vamos a insistir principalmente en éste último dado que lo consideramos necesario para entender los diferentes significados, atribuidos por el mundo liberal, a conceptos políticos clave utilizados durante la elaboración de la Constitución de Cádiz.

Para llevar a cabo el presente estudio, se utilizarán principalmente las obras de Francisco Martínez Marina Principios naturales de la moral, de la política y de la legislación ${ }^{17}$ y de Joaquín Lorenzo Villanueva Las angélicas fuentes o El Tomista en las Cortes $^{18}$ y se buscará cómo los significados que esos autores atribuyen a los

ganización social y política (GONZÁLEZ MANSO, A. I. (2011). «Principios políticos de Alberto Lista. Un análisis conceptual e histórico», Revista de Estudios Políticos, 152 (abril-junio), 143-181.

15 PORTILLO, Revolución de nación, establece dos esferas de actuación del catolicismo por parte liberal: una esfera que afectaría al orden social y en la cual se integrarían las ideas de un orden universal dispuesto por Dios y una esfera de orden político sobre la cual se insertaría el tratamiento constitucional realizado por los hombres (369). En el presente artículo pretendemos mostrar que quizás las dos esferas estén más estrechamente vinculadas condicionando la primera el significado de los conceptos políticos.

16 VARELA SUANZES, J (2007). «Algunas reflexiones metodológicas sobre la Historia Constitucional», Historia Constitucional (revista electrónica), 8, 245-259, 246-249. http://hc.rediris.es/08/index.html.

17 MARTÍNEZ MARINA, F. (1933). Principios naturales de la moral, de la política y de la legislación [1823-1824], Madrid, Academia de Ciencias Morales y Políticas.

18 VILLANUEVA, J. L. (1849). Las angélicas fuentes o El Tomista en las Cortes [1811-1813], Madrid, Imprenta a cargo de D. Celestino G. Álvarez. 
conceptos de libertad, soberanía, voluntad general...se encuentran en los debates parlamentarios durante la elaboración de la Constitución de $1812^{19}$ así como en la prensa de la época ${ }^{20}$. El trabajo estará centrado principalmente en aspectos doctrinales, en particular del mundo de las creencias religiosas y en cómo éstas influyeron en el momento de dotar de significado a los nuevos conceptos políticos.

\section{MORAL Y RELIGIÓN}

El punto de partida esencial en el pensamiento de Martínez Marina y de Villanueva es la existencia de una ley natural y divina de la que deriva toda explicación de la sociedad y de la política ${ }^{21}$ : «Existe una ley universal, inmutable y eterna; ley que constituye un derecho primordial, fuente de todos los derechos, principio y regla de toda Moral y de toda Política, de que resulta un vínculo que ata la sociedad de todos los hombres; ley que no puede ser derogada ni añadida, ni mudada por otras leyes expresas, ni por el uso o costumbre contraria; ley de la cual ni el Senado ni el pueblo puede dispensarnos, y que es idéntica en Atenas y en Roma; la misma hoy que en los tiempos pasados y en los venideros. Esta ley sempiterna e inmortal como su autor, que es Dios emperador de todos, subsistirá en todas edades y tiempos y comprenderá todas las gentes y naciones. La recta razón de cada uno es como el intérprete y común maestro de esta ley; no conformarse con ella es envilecer la dignidad humana, y dejar de ser hombre» ${ }^{22}$.

${ }^{19}$ No pretendemos en la línea de J. I. SÁNCHEZ AMOR buscar las influencias de Marina en los diputados gaditanos sino más bien mostrar cómo el pensamiento católico, y su influencia en el significado de los conceptos políticos, de Marina o de Villanueva es compartido por gran parte del mundo liberal en contraposición con el mundo tradicional (SÁNCHEZ AMOR, J. I. (1988). «Algunas consideraciones sobre la influencia de Martínez Marina en las Cortes de Cádiz», Revista de Estudios Políticos, 62 (Oct-Dic), 89-129).

20 Se utilizarán los Diarios de Sesiones de las Cortes Generales y Extraordinarias (DSC) (18701874), Madrid, imprenta de J. A. García así como los periódicos El Espectador Sevillano (EES)(18091810), no 1 (2/10/1809) al 119 (23/1/1810), Sevilla, imprenta de Hidalgo, El Tribuno del Pueblo Español (ETPE), $\mathrm{n}^{\circ} 1(3 / 11 / 1812)$ al no $62(30 / 7 / 1813), 1^{\circ}$ época y $\mathrm{n}^{\circ} 1(13 / 7 / 1813)$ al $\mathrm{n}^{\circ} 35$ (5/11/1813), 2 época, Cádiz, imprenta Tormentaria, El Procurador General de la Nación y del Rey (PGNR), no 1 (1/10/1812) al no 327 (23/8/1813), Cádiz, imprenta de la Viuda de Comes y 2 a $4^{\mathrm{a}}$ época (16/1/1814-27/4/1815), Madrid, imprenta Dávila.

${ }^{21}$ También podemos encontrarla en J. CANGA ARGÜELLES, constituyendo su punto de partida, junto al pactismo resultante, para llevar a cabo su definición de soberanía, libertad...así como para establecer la organización política (CANGA ARGÜELLES, J. (2000). Reflexiones sociales y otros escritos [1811], Madrid, Centro de Estudios Políticos y Constitucionales, 2-93, 19).

${ }^{22}$ MARTÍNEZ MARINA, Principios, 193; y VILLANUEVA, Las angélicas fuentes, 104. 
De igual modo Martínez Marina vincula estrechamente la Moral y la Política: «La Política (es) la Moral aplicada al gobierno de los Estados» ${ }^{23}$, moral que está íntimamente ligada con la práctica de la virtud: «A la Moral corresponde demostrar sus ventajas (de la práctica de la virtud); a la Educación, sembrar y cultivar sus principios, a la Costumbre, hacer su práctica familiar; a la opinión pública y al ejemplo, apoyarla y sostenerla; a la Legislación, darle sanción de la autoridad; al Gobierno, hacerla más eficaz y persuasiva con el auxilio de las recompensas...En suma, la sana Política debe siempre girar sobre esta base: que la grandeza, gloria y prosperidad de los Estados está íntima y esencialmente enlazada con las buenas costumbres, y que ningún pueblo, ningún soberano, ningún hombre puede ser feliz sin la virtud» ${ }^{24}$.

En esta línea, Martínez Marina equipara libertad natural con libertad política: la libertad es natural porque «precede a todas las instituciones humanas, a todas las leyes positivas, a todos los pactos y convenciones facticias, y a todos los gobiernos políticos; natural, porque es inseparable del hombre», estando presente tanto en el estado de naturaleza como en una sociedad política ${ }^{25}$. Pero «ser libre no consiste en hacer lo que se quiere, sino lo que se debe y es capaz de contribuir a la consecución de un bien sólido y permanente» ${ }^{26}$; de aquí su crítica a Bentham por su dependencia de la libertad de las leyes o a Destut de Tracy por su idea de omnilibertad (que para Martínez Marina es equivalente de anarquía). De igual modo, aunque aparentemente cerca del pensamiento de Rousseau, para el cual la libertad en sociedad está condicionada por ciertas reglas, para Martínez Marina la libertad sigue siendo total por ser natural y orientada exclusivamente al bien común $^{27}$. Frente a la definición de Montesquieu de que la libertad es el derecho de hacer todo lo que las leyes permiten, para Martínez Marina «la libertad natural es obra de la ley eterna, de la razón y de la moral; la libertad civil es producto de la ley positiva, la cual, aunque tiene el mismo objeto que la moral, pero no la misma extensión» ${ }^{28}$. Así las leyes positivas vendrían solo a reforzar los principios naturales que miran al bien común y por tanto al bien general del Estado.

Con respecto al origen y fundamento de la sociedad civil, para Martínez Marina todos los gobiernos conocidos y la autoridad de los soberanos radican en las leyes fundamentales de las naciones que son resultados de pactos y convenciones primi-

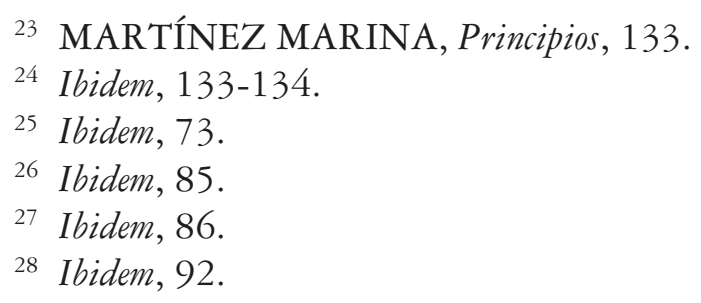


tivas: «El contrato social bien se puede decir, en cierto sentido, que comenzó con el mundo; y aunque sus cláusulas no hayan sido expresadas ni consignadas (...) subsistían grabadas en el fondo del corazón y en el código de la naturaleza, anterior a todas las cartas, diplomas y códigos $»^{29}$. Pero así mismo ningún pacto puede obligar al hombre a violar la ley natural, a ir en contra de las leyes eternas de justicia y de los principios de la Moral y de la Religión. Un gobierno así concebido conduciría al estado a su decadencia y destrucción ${ }^{30}$. Por ello «existe, pues, o debe existir un enlace sensible, una conexión esencial entre las leyes de la Religión, de la Naturaleza y de la Moral, y entre las instituciones y leyes civiles y políticas, las cuales nunca debieron considerarse sino como complemento de aquellas y como una potencia coactiva y un medio de obligar al hombre a la observancia de aquellas leyes constitutivas de su existencia moral y base indiscutible del orden público y de la felicidad de las naciones y de todo Gobierno justo y templado» ${ }^{31}$. Así «la Constitución del Estado y las leyes son la base de la pública tranquilidad y la más firme garantía de la libertad de los ciudadanos» estando obligados a obedecerlas y respetarlas siguiendo «el principio consagrado por la Religión, por la Moral y por la Política» ${ }^{32}$. En el mismo sentido Villanueva considera que pueden equipararse ley con expresión de la voluntad general, siempre que se entienda ésta como «lex est constitutio populi»: «la ley civil es la expresión de la voluntad general del pueblo, esto es, una constitución hecha por el pueblo. Porque lo demás de que sea justa y ordenada al bien común lo envuelve en si la naturaleza misma de la ley» ${ }^{33}$.

De esta manera Martínez Marina critica el contrato de Hobbes, de Locke y el de Rousseau; éste último fundamentalmente porque presupondría que el hombre solo toma conciencia de las grandes ideas de Moral y de Política en el momento de salir del estado salvaje, lo cual supone para nuestro autor una negación del carácter eterno de las mismas ${ }^{34}$. Para Villanueva la crítica fundamental radicaría en la negación de Rousseau del carácter sociable del hombre y así pues de la esencia natural de la sociedad ${ }^{35}$. De aquí se deriva que para ambos autores es totalmente aceptable la soberanía popular: no es ninguna novedad ni va en contra de la Religión

29 Ibidem, 338.

30 Ibidem, 354.

31 Ibidem, 365; podemos observar los mismos principios en I. GARCÍA MALO y que podrían resumirse: «En una palabra, el gobierno está establecido para obligar a los hombres en sociedad a practicar los deberes de la moral» (GARCÍA MALO, I. (1811). La política natural o discurso sobre los verdaderos principios del gobierno, Mallorca, Imprenta de Miguel Domingo, 220).

32 MARTÍNEZ MARINA, Principios, 268-269.

33 VILLANUEVA, Las angélicas fuentes, 60.

34 MARTÍNEZ MARINA, Principios, 333.

35 VILLANUEVA, Las angélicas fuentes, 88. 
dado que interpretan que «la soberanía reside esencialmente en la Nación» como un derecho natural que proviene de $\operatorname{Dios}^{36}$. Así para Villanueva «la nación no puede enajenar la potestad de gobernar que esencialmente reside en ella, pero puede depositar en quien halle conveniente el poder de ejercerla (...) El poder de los reyes considerado en si mismo viene inmediatamente de Dios pero considerado con respecto a su procedencia, viene inmediatamente de la sociedad y mediatamente de Dios $»^{37}$. En Martínez Marina se percibe un cierto temor por lo que se puede entender por soberanía popular dado que su obra la escribe en 1823-24 tras la formación de la Santa Alianza en Europa; sin embargo él sigue defendiendo que su interpretación, como la de Villanueva, no entraña ningún peligro para el Estado: «la Soberanía del pueblo bien definida no es la anarquía ni una democracia tiránica, así como la Libertad no es la licencia, ni la Religión es el fanatismo» ${ }^{38}$. Este principio, que se acomoda a todos los Estados y a todas las formas de gobierno, no es una invención humana, no es la soberanía de Hobbes o de Rousseau. Su definición puede recordar a la de Rousseau: en la sociedad política los hombres reúnen «sus facultades, sus derechos, voluntades y fuerzas para aumentar su poder y crear una masa de fuerza pública superior a la de los particulares» ${ }^{39}$. Pero esta sociedad, depositaria de los derechos individuales no puede regirse por un criterio de utilidad ${ }^{40}$ (como defiende Bentham), ni por la defensa de intereses particulares (como defiende Locke), dado que no debe «desviarse de los principios de orden moral, ni traspasar los límites demarcados en la carta de naturaleza por el Supremo legislador ${ }^{41}$. Su crítica a Bentham radica en que «reduce la Moral a una especulación mercantil, a una negociación de interés, a una ciencia del cálculo» ${ }^{42}$, mientras que Martínez Marina considera que es imposible comprender el verdadero y sólido interés de la utilidad pública sin el auxilio de la ley natural, de la Religión y de la Moral ${ }^{43}$.

36 MARTÍNEZ MARINA, Principios, 277.

37 VILLANUEVA, Las Angélicas fuentes, 100.

38 MARTÍNEZ MARINA, Principios, 318.

39 Ibidem, 322. De hecho FERNÁNDEZ ALBALADEJO, «Observaciones», 713, también ve en Martínez Marina un acercamiento al pensamiento de Rousseau que se enmarcaría en lo que denomina «Cristianismo Cívico»; PORTILLO, Revolución de nación, 341, coincide en que los liberales pueden estar dando una interpretación de la voluntad general como de «un acto colectivo de definición de lo justo».

40 MARTÍNEZ MARINA, Principios, 161.

${ }^{41}$ Ibidem, 324.

42 Ibidem, 177.

${ }^{43}$ En este mismo sentido lo hace A. Lista en GONZÁLEZ MANSO, «Principios políticos», 150 , que centra la organización social en aspectos morales y religiosos frente al utilitarismo de aspectos económicos. 
Por su parte Villanueva, apoyándose en Santo Tomás sería favorable a una monarquía mixta, con limitación del poder del rey y derecho de rebelión para evitar comportamientos tiranos del soberano: «conviene que el rey tenga mayor poder que muchos de sus súbditos juntos...pero este poder debe ser menor que el de toda la multitud de su reino» ${ }^{44}$. Estas limitaciones son las que equipara con soberanía de la nación por lo cual las Cortes gaditanas estarían contemplando establecer una monarquía templada «como lo ha sido siempre» ${ }^{45}$. Es en el fondo una adaptación del pactismo medieval y del contractualismo iusnaturalista a las nuevas circunstancias políticas ${ }^{46}$, donde la separación de poderes tiene como base la complementariedad de virtud de todos los participantes ${ }^{47}$.

Como podemos apreciar la concepción política de la sociedad, y, así pues, todas las ideas de autores como Locke, Rousseau, Montesquieu, aparecen filtradas a través de una concepción del derecho natural, donde la Moral y la Religión y la consecución de un Bien Común son la causa primera y última de toda decisión e interpretación. Se ha interpretado como «antigua» cualquier reflexión que mencionase derechos naturales, moral, religión cuando en realidad hay que hacer una distinción fundamental en función de quién la utilice y el significado que le de. Como veremos, esta interpretación difiere de la mantenida por el elemento más conservador. Para esta tendencia ideológica, la Religión y la Política permanecen las mismas de siempre, sin ese esfuerzo de simbiosis (realizados por autores como Martínez Marina, Villanueva o Lista) entre un derecho natural y los nuevos significados atribuidos a conceptos como soberanía o libertad. Esa simbiosis que será retomada en sus argumentaciones por numerosos liberales, dado que permite conciliar un sentirse católico con una concepción política moderna.

\section{DEBATES PARLAMENTARIOS Y PERIODÍSTICOS}

La exaltación de la Moral y de la virtud se proyecta en los debates parlamentarios durante la redacción de la Constitución de 1812 así como en las controversias reflejadas en los periódicos de la época.

En primer lugar podemos observar una vinculación de moralidad con legitimidad, es decir ésta última no viene determinada únicamente por el articulado de

44 VILLANUEVA, Las Angélicas fuentes, 52.

45 Ibidem, 48.

46 MARTÍNEZ MARINA, Principios, 330: todos los gobiernos se han formado en virtud de pactos expresos y tácitos con consentimiento voluntario y espontáneo.

47 VILLANUEVA, Las angélicas fuentes, 55. 
la Constitución, necesita «un plus» definitivo que la consagre, y este plus es la virtud. Así tenemos la reflexión de A. Lista: «Desengañémonos: es imposible que los agentes legales de una constitución basten solos a formar un pueblo y conducirlo a la libertad y a la felicidad: es necesario contar con la influencia de los agentes morales; y entre estos, no hay alguno más acomodado a nuestra situación y al estado presente de las costumbres europeas, que la opinión pública» ${ }^{48}$.

De igual modo el derecho natural es reivindicado como fuente de legitimidad y de continuidad por parte liberal aunque siguiendo dos argumentaciones diferentes: una contenida en El Tribuno del pueblo español, donde se propone que el nuevo código legal no solo debe basarse en las leyes anteriores, sino también en el derecho natural, la filosofía moral para así conseguir reflejar el espíritu de la nación: «Pienso al contrario que cuantas leyes, cédulas, pragmáticas y decretos tenemos, son otros tantos materiales que deben estudiarse, reflexionarse y rumiarse, así como la historia del Reino, para sacar de todos, y del derecho natural, y filosofía moral, principios de justicia, equidad, industria, costumbres, etc, análogas y correspondientes al carácter, clima y situación de la Nación; y que estos principios (...) son los que deben formar el referido código, quedando cuantos ahora cargan nuestras librerías derogados, nulos, de ningún valor y efecto, en cuanto a ser leyes, y solo en la clase de monumentos históricos; ${ }^{49}$ la otra, la defendida por A. Lista: «Parece que no debemos mirar nuestra antigua legislación constitucional como un modelo al cual obedezcamos ciegamente, así como tampoco debemos enteramente abandonarla. Seamos justos e imparciales, y siguiendo los principios generales y primordiales del derecho natural, establezcamos la sociedad, si no sobre las basas que ha tenido en otras épocas, sobre las basas que ha debido tener en todas» ${ }^{50}$.

El aspecto moral condiciona la interpretación de la libertad. Ésta puede entenderse bajo dos perspectivas: la conservadora donde «La piedad religiosa, esta virtud, origen y fuente de las buenas costumbres, es la única precaución constitucional que puede conservarnos la libertad $»^{51}$; o la liberal donde es frecuente asociar la igualdad ante la ley con la justicia moral: Luján refiriéndose a los repartimientos de conquista, se pregunta, « ¿fue justo que solo entre ellos se divi-

48 «Cuestiones importantes sobre las Cortes (Cuestión IX ¿Como deberá formarse la diputación que ha de quedar después de disueltas las cortes? ¿Y qué poderes se le deberán conferir?)(cont.)», EES, 22/1/1810, n 113, 447.

49 «Política: Continúa el discurso en que se demuestra con documentos y escritos anteriores a la revolución, que las reformas en que se emplea el congreso nacional han sido propuestas a nuestros Reyes y promovidas por sus consejos y tribunales», ETPE, 19/10/1813, no 29, 482-483.

50 «Del espíritu público de las naciones (cont.)», EES, 23/10/1809, nº 22, 85-86.

51 Llamas, DSC, 28/8/1811, no 330, 1714. 
diese el fruto de la conquista, sin contar en cosa alguna con los soldados que derramaron su sangre en la batalla, que llevaron las fatigas más afanosas y que sufrieron aquellos trabajos?» ${ }^{52}$.

La falta de virtudes en una sociedad (como ha ocurrido durante los tres siglos de despotismo) conduce a una menor conciencia de los derechos individuales, a la corrupción de las costumbres y por tanto a la destrucción de la sociedad ${ }^{53}$. En realidad las semillas del bien, de la virtud, de la verdad, de la sabiduría «yacen sepultadas en el fondo de nuestro corazón»; la ignorancia y el error son la fuente de todos los males en el orden moral, de aquí la importancia que otorga Martínez Marina a la instrucción como vía de alcanzar la perfección natural del hombre: «la razón cultivada es el antídoto más poderoso contra la corrupción de costumbres, que la virtud es una exótica y rara, que no puede echar hondas raíces en un terreno inculto, ni prosperar sino bajo el influjo benéfico de la verdad y de la sabiduría, y que una buena y sabia educación es la que decide infaliblemente de la suerte de los hombres» ${ }^{54}$.

Aunque tanto por parte liberal como por parte conservadora se pretende marcar distancias con las ideas extranjeras (en particular con las de Francia tras los hechos ocurridos durante la Revolución), por parte liberal en realidad se readaptan parte de esas ideas con los principios neoescolásticos y la religión, mientras que por parte conservadora se produce un neto rechazo a las mismas: «Señor, todos los males que nos afligen, la ignorancia, el atraso en la literatura y demás ramos, nos vienen de la Francia, cuyo influjo pestilencial en la Península ha hecho degenerar nuestras antiguas costumbres y adoptar mil perniciosas ideas que tienden a exaltar las cabezas y trastornar todos los principios más sanos, sancionados por todas las naciones cultas en todos los siglos ilustrados» ${ }^{55}$. Para los conservadores la religión (más bien convendría decir la Iglesia, tal y como se ha entendido hasta el momento) está en el centro de todo y hay una marcada desconfianza de que la nueva Constitución la proteja realmente ${ }^{56}$. Lo mismo ocu-

52 Luján, DSC, 4/6/1811, n 246, 1181.

53 «De los gobiernos representativos (cont.)», EES, 20/11/1809, n 50, 199; CANGA ARGÜELLES, Reflexiones, 37.

${ }^{54}$ MARTÍNEZ MARINA, Principios, 126. La importancia de la virtud en la construcción de una nación que FERNÁNDEZ ALBALADEJO, «Observaciones», 707, asimila con el moralismo republicano, la atribuye a la influencia de Mably sobre Martínez Marina. Pero como también destaca FERNÁNDEZ ALBALADEJO esta virtud no respondía a una táctica política, se basaba en los principios del cristianismo que Martínez Marina desarrolla ampliamente en La Historia de Nuestro Señor Jesucristo (707-708).

55 Ostolaza, DSC, 6/6/1811, no 248, 1194.

56 PGNR, 22/4/1813, n 203, 1677. 
rre con las referencias al derecho natural: éstas sirven para reforzar lo expresado en los antiguos códigos (la legitimidad viene no solo de la continuidad en el aspecto legal histórico, sino también de la sanción divina expresada en este derecho natural) no para readaptarlas a las nuevas condiciones políticas. Los derechos naturales sirven de elemento vinculante con el pasado sin aportar ningún tipo de reinterpretación modernizadora: «y con ello aparece que dicho artículo de la Constitución restablece los principios de derecho natural, y las disposiciones de nuestras antiguas Cortes» ${ }^{57}$.

\section{CONSECUENCIAS EN EL SIGNIFICADO DE LOS TÉRMINOS POLÍTICOS}

Vamos a observar cómo la manera de entender la Religión va a condicionar por parte liberal y conservadora el significado atribuido a los conceptos políticos debatidos en las Cortes gaditanas. En primer lugar se va a considerar qué entiende el mundo liberal por Religión e Iglesia.

\section{Sentimiento religioso versus Iglesia}

Sin entrar en el aspecto concreto de las reformas llevadas a cabo por las Cortes sobre el elemento eclesiástico, se puede observar una distinción neta por parte del elemento liberal entre sentimiento religioso y la interpretación del papel de la Iglesia en la Historia y en el presente, posiblemente siguiendo una interpretación más introspectiva de la religión (en una línea cercana al jansenismo). La situación de abusos por parte de la Iglesia del antiguo régimen hacía imprescindible el acometer toda una serie de reformas radicales de la misma; pero al tiempo estas reformas eran llevadas a cabo por individuos plenamente católicos: «se verá que nuestras antiguas Cortes, no menos celosas ni católicas que las actuales...» ${ }^{58}$. Medidas que por parte conservadora serán interpretadas como fruto de libertinos: «ese monstruoso Dragón de la secta francmasónica que reúne la astucia y delirios de los herejes antiguos y modernos» ${ }^{59}$. Incluso de no católicos: « ¿Se despidieron de Dios al tomar asiento en el Congreso?» ${ }^{60}$. Esta postura se ra-

\footnotetext{
57 Borrull, DSC, 17/3/1812, n ${ }^{\circ} 523,2941$.

58 Giraldo, DSC, 14/5/1813, no 852, 5277.

59 «Articulo comunicado firmado El Minador» en $P G N R, 22 / 12 / 1812, \mathrm{n}^{\circ} 83,666$.

60 «Exposición contra el informe...(cont.)» en PGNR, 6/1/1813, n 98, 788.
} 
dicalizará tras la abolición por parte de Fernando VII de la Constitución y de los decretos aprobados por los diputados: así desde las páginas del Procurador se incita al rey a la represión de los liberales tal y como Dios lo hizo en el Antiguo Testamento: « ¿Tendrá pues V.M. repugnancia y horror en imitar la conducta de Dios y de sus santos? ${ }^{61}$. Represión que estaría plenamente justificada por su intento de acabar, a través de las reformas aprobadas en Cortes, con la Iglesia: «Si dura esta protección por más tiempo, no queda fraile, convento, canónigo, obra pía, rentas eclesiásticas, que no hubieran abolido ${ }^{62}$.

La solución de separar Religión de Iglesia así como de vincularse con la Iglesia primitiva, a la que llegó el mundo liberal, les permitió salvar el escollo moral de tomar medidas contra la Iglesia. Así Villanueva como Lista no ven ninguna contradicción entre catolicismo y crítica a instituciones o prácticas de la Iglesia en el pasado. Villanueva, pidiendo la abolición del Voto de Santiago afirma que el que se llamen votos no prueba que sean promesas hechas a Dios, «lo que prueba es que habiéndose oscurecido u olvidado su origen, la falta de ilustración o alguna otra causa, ha contribuido a que los pueblos se crean obligados al pago de esta contribución, en virtud de una promesa nacional que no existe» ${ }^{63}$.

Por otra parte, otro aspecto que ayuda a resolver la misma problemática nos la presenta Martínez Marina al destacar que no hay que confundir religión con superstición: la Moral religiosa permite, por la vía del remordimiento, limitar los excesos que se cometerían si uno creyese que no iba a ser descubierto por la socie$\mathrm{dad}^{64}$. Si se producen crímenes en naciones religiosas es porque no se conocen bien la Religión ni las máximas de la Moral religiosa: «Generalmente en todo país el pueblo es muy devoto, muy crédulo, muy celoso de su religión (...) pero en realidad permanece en una completa ignorancia de la Religión, de la que apenas conoce más que el nombre, y de los principios de la sana Moral ${ }^{65}$. En este mismo sentido se puede interpretar el discurso de Caneja y Ruíz Padrón sobre el voto de Santiago: «Por lo mismo que soy eclesiástico y cura, quisiera derribar de un golpe el ídolo desde sus cimientos. Como eclesiástico, porque debo despreciar todo acontecimiento prodigioso que no se halle apoyado con la autoridad y decisión de la Santa Madre Iglesia (...) y como cura, para aliviar las lágrimas de mis feligreses (...) Ya es tiempo de no confundir la sana devoción con el interés, la verdadera piedad con la superstición. Ya es tiempo de distinguir las venerables tradiciones apostólicas y

${ }^{61}$ PGNR, 28/3/1815, no 87, 690.

62 DE VÉLEZ, Apología, 205.

${ }^{63}$ Villanueva, DSC, 12/10/1812, no 677, 3809-3810.

64 MARTÍNEZ MARINA, Principios, 210.

65 MARTÍNEZ MARINA, Principios, 212. 
eclesiásticas de las tradiciones populares, que son las únicas bases y fundamentos de este decantado voto» ${ }^{66}$. En un sentido más irreverente, y poco frecuente en este tipo de discursos, se manifestaba Capmany: «iSí es vuestro el interés, y vuestra la honra, yo os invoco santo Apóstol! ¿Por qué no os aparecéis aquí ahora, así como os presentasteis al Rey Ramiro, para sacarnos de dudas y aquietar nuestra conciencia?»; aunque suaviza su reflexión «Si pareciere que este modo de raciocinar tiene algún aire de poca piedad, responderé que el santo Apóstol es patrón de España, y lo será eternamente; título glorioso, que jamás perderá ni se enfriará la devoción de los españoles por la legitimidad ni ilegitimidad del privilegio; y tan patrón será manteniéndose los canónigos con moderadas rentas, como con espléndida vida» ${ }^{67}$.

Por parte del elemento conservador se tiende, al contrario, a asociar estas creencias milagrosas con la verdadera religión y piedad: así Ostolaza, refiriéndose también a la abolición del Voto de Santiago, afirma que dicha abolición sería irreligiosa «porque atacaba indirectamente a la piadosa creencia en que estamos los verdaderos españoles de que Santiago asistió a la batalla de Clavijo (...) creencia piadosa que ha surtido efectos prodigiosos en todos tiempos, que ha exaltado los ánimos de todos en las campañas, y que llena de consuelo a las almas buenas, como de emulación a los extranjeros que se han dedicado a combatirla» ${ }^{68}$.

El artículo 12 de la Constitución al declarar la Nación católica excluyendo cualquier otro culto, ha dado lugar a todo un debate sobre cómo explicar esta aparente intolerancia con la declaración de derechos y libertades que hace la Constitución gaditana. Sin pretender repetir las argumentaciones de Portillo Valdés ${ }^{69}$, que compartimos totalmente, es preciso destacar en la invocación trinitaria previa al texto constitucional, la voluntad de diputados de diferente tendencia ideológica, de ampliar esta invocación poniendo también la Constitución bajo la protección de Jesucristo, la Virgen María ${ }^{70}$, los misterios ${ }^{71}$ o de todas aquellas profesiones de fe manifestadas en códigos anteriores ${ }^{72}$. Quizás la aparente contradicción del artículo 12

${ }^{66}$ Caneja (leyendo y condividiendo el discurso de Ruiz Padrón), DSC, 12/10/1812, 677, 3814.

67 Capmany, DSC, 13/10/1812, n ${ }^{\circ}$ 678, 3824-3825.

68 Ostolaza, DSC, 12/10/1812, n 677, 3815.

69 PORTILLO, «De la monarquía católica», centra en particular en este artículo la transición de un catolicismo vinculado a la monarquía a la nación (20) y convirtiéndose en un rasgo identificativo de españolidad y de ciudadanía (22). De hecho para este autor este «artículo $12-\mathrm{y}$ todo el corolario de confesionalidad de la Pepa— conformara una pieza más del engranaje de conexión entre nación y soberanía» (28).

70 Villanueva, DSC, 25/8/1811, no 327, 1686.

${ }^{71}$ Guereña, DSC, 25/8/1811, no 327, 1685.

72 Riesco, DSC, 25/8/1811, no 327,1685 . La principal diferencia en esta postura de ampliar las invocaciones radica precisamente en la vinculación por parte conservadora con los códigos antiguos. 
con la defensa de las libertades, queda perfectamente explicada por Villanueva, que posiblemente representa el sentir de la mayoría católica liberal: «Notorio es que la España católica desde Recaredo hasta D. Fernando y Doña Isabel, al paso que profesaba como dominante nuestra santa religión, no excluyó absolutamente a todos los sectarios» ${ }^{73}$; se fijaban solo las condiciones para tolerarlos. Es el modo que tuvieron los liberales de integrar el catolicismo de la sociedad española en el edificio constitucional que se estaba creando siguiendo la línea marcada por Martínez Marina de establecer un fuerte vínculo entre «las leyes de la Religión, de la Naturaleza y de la Moral, y entre las instituciones y leyes civiles y políticas».

El debate sobre la abolición de la Inquisición, y su papel relevante en la protección de la religión, refleja las diferentes maneras de entender este artículo 12. Sin entrar en un análisis pormenorizado del debate sobre la Inquisición ${ }^{74}$, es preciso destacar que existe, tanto por parte de liberales como de conservadores, una voluntad de entroncar con el pasado, aunque difieren en el periodo histórico considerado según la posición ideológica mantenida: por parte liberal, la vinculación es con la Iglesia anterior a la creación de la Inquisición; por parte conservadora con la posterior. En primer lugar el informe de la Comisión destaca: «la voluntad general de la Nación (es) que se conserve pura la religión católica; que sea protegida por leyes sabias y justas, y que no se permita en el Reino la profesión de otro culto (...) Ninguno puede negar la necesidad de la religión para conservar el orden publico, mantener las buenas costumbres, y dar firmeza y estabilidad a las leyes.» La religión católica se adapta a toda forma de gobierno; es la ley civil la que admite o excluye de los Estados la diversidad de religiones. Desde el tercer Concilio de Toledo, la religión católica ha sido, por ley fundamental, la religión de la Monarquía, siendo protegida por la autoridad civil de maneras diferentes según los tiempos. La Constitución actual refleja las leyes que estaban «grabadas en los corazones de todos los españoles, por las que han suspirado en todos tiempos» ${ }^{75}$. Nos interesa destacar el argumento, utilizado frecuentemente por otros autores, de que la religión católica no es tolerante ni intolerante y que es imprescindible para el mantenimiento de cualquier sociedad. La intolerancia de cultos está exclusivamente relacionada con una cuestión de protección de la religión y de mantenimiento del orden ${ }^{76}$. La

73 Villanueva, DSC, 18/8/1813, 5992.

${ }^{74}$ Perfectamente analizado todo el debate en las Cortes como en los periódicos por ESCUDERO, J. A. (1991). La abolición de la Inquisición Española. Discurso leído el día 2 de Diciembre de 1991, en su recepción pública, Madrid, Real Academia de Jurisprudencia y Legislación.

75 Comisión, DSC, 8/12/1812, discusión del proyecto de decreto sobre el Tribunal de la Inquisición (sobre los tribunales protectores de la religión), 4190-4191.

76 Ibidem, 4192. 
convivencia de religiones en el pasado solo fue posible mientras no originó una alteración del orden, pero constituía un problema latente: por las leyes de Partidas se permitía la existencia de moros y judíos, incluso sus cultos gozaron de fueros particulares. Pero «eran dos pueblos (católicos y no católicos) separados por ley y costumbres, y al mismo tiempo se intentaba que fuesen uno solo» ${ }^{77}$. Pero esta argumentación no conduce a la justificación de la existencia de la Inquisición, porque atenta contra los principios defendidos en la Constitución: se recurre a delegar en los Obispos la función de control de las posibles herejías. Argüelles insiste en la utilización partidista de la religión por parte de Fernando el Católico con la finalidad exclusiva de reforzar su poder: «La religión fue el pretexto en este Príncipe para introducir una medida que al principio parecía solo dirigida contra los que excitaban la animosidad nacional, que con tanta astucia y artificio se procuraba excitar, pero que en realidad, después de adoptada sin recelo ni sospecha, iba a poner en las manos del Rey un medio seguro de hacerse formidable y absoluto, como lo fueron él y sus sucesores ${ }^{78}$.

Por parte conservadora se insiste en la necesidad de la Inquisición dada la persistencia de las herejías que hacen peligrar la religión: «La herejía se ha presentado en toda Europa disfrazada con las máximas políticas, y los más dulces nombres de la libertad y la igualdad $»^{79}$. De igual modo Borrull la considera la mejor institución para apoyar la religión católica y conseguir la eterna felicidad: «Sus procedimientos se han dirigido siempre, no al castigo, y sí a la conversión de los herejes, y reducirles al camino que guía a la eterna felicidad ${ }^{80}$. En su caso la asociación entre las nuevas ideas filosóficas y la herejía es total: «Reunidos los profesores de diferentes sectas en Francia, han triunfado del poder de los Obispos, establecido la filosofía y el ateismo sobre las ruinas de la verdadera religión, destruido la Monarquía, y corriendo por toda la Península han propagado sus detestables máximas, y corrompido un sinnúmero de gentes; llegando las cosas a tal extremo, que, a vista de V.M., se publican infames escritos contra nuestra santa religión, y se insulta a los maestros de la ley, a los venerables Prelados que la defienden ${ }^{81}$. Y concluye: «La cosa es muy clara; el principal fin que debemos tener

77 Ibidem, 4193; en el mismo sentido Ruíz Padrón, 18/1/1813, Sobre el Tribunal de la Inquisición, 4353: existió convivencia sin graves casos de herejía gracias al control de los Obispos tal y como se quiere recuperar para el presente.

78 Argüelles, DSC, 9/1/1813, Sobre el Tribunal de la Inquisición, 4254.

79 Hermida, DSC, 8/1/1813, Sobre el Tribunal de la Inquisición, 4241, en el mismo sentido Riesco, 10/1/1813, 4279.

${ }^{80}$ Borrull, DSC, 19/1/1813, Sobre el Tribunal de la Inquisición, 4379.

81 Ibidem, 4381. 
es la conservación de la religión; a él ceden todos los respetos e intereses humanos» ${ }^{82}$.

Es importante destacar cómo, en el tema de la Inquisición, se hace un llamamiento al sentimiento religioso de la población. La religión es un elemento distintivo de la población española que hay que defender. Pero para el elemento conservador: «los novadores ocultan todo su veneno: son lobos devoradores que se revisten de piel de ovejas, esto es, se publican a boca llena católicos: aparentan piedad, aunque no la conocen: propalan máximas de libertad y felicidad: dicen con astucias que no combaten los dogmas ni la moral, mas que hay ciertos abusos que es necesario reformarlos, y como si tuvieran la misión correspondiente, se hacen reformadores, siendo más bien destructores de las máximas existentes, y de los medios de conservarlas» ${ }^{83}$. Valoración de la cual se lamenta el elemento liberal: «no puede decirse que los pueblos estén por la Inquisición, sino en cuanto se les quiere hacer creer que no hay otro medio para que sus hijos sean católi$\cos »^{84}$. Para Capmany el apoyo, si se produce, es solo por ignorancia del pueblo: «Qué empeño en hacer sinónimos las palabras Inquisición y Religión, Santo Oficio y Fe católica?(...) Con esta ignorancia es fácil espantar y desconsolar a las almas piadosas e inocentes. «¡Os van a quitar la religión santa de vuestra Patria!» les predican pública y privadamente (...) Y no hay quien les responda: «nosotros no necesitamos de Inquisición para ser católicos», esto es injuriarnos, es injuriar a nuestros padres que la practicaron por medio de la instrucción, y no por la amenaza del castigo» ${ }^{85}$. Finalmente el Decreto para la abolición del Tribunal de la Inquisición, así como el Manifiesto posterior, fueron leídos en todas las parroquias durante tres domingos seguidos por orden del Arzobispo de Toledo: «para instruir al pueblo de una doctrina que hasta entonces le era desconocida, y no por eso dejaba de estar apoyada en los cánones y disciplina de la Iglesia» ${ }^{86}$.

\section{Conceptos políticos}

Por parte conservadora se interpreta el artículo 3 de la Constitución «que ahora la potestad, soberana es derivada de Dios a los Reyes, mediante el pueblo, en quien se dice residir primaria y esencialmente» ${ }^{87}$; o la interpretación de Lla-




mas: «la Nación española es aquel cuerpo moral que forman el pueblo español y el Soberano español como su cabeza, y que constituyen lo que llamamos Monarquía española ${ }^{88}$.

Por parte liberal el cuerpo moral rousseauniano permite interpretaciones radicales de la soberanía al tiempo que incorpora el elemento moral que tranquiliza el sentimiento católico ${ }^{89}$. Se produce un traspaso de los derechos naturales del hombre a la Nación: «recobrar los naturales, inherentes e imprescriptibles derechos a la Nacion, conforme al espíritu de sus leyes» ${ }^{90}$. Portillo Valdés considera que la vinculación con el catolicismo (entendido por nuestra parte en un sentido amplio que comprendería los derechos naturales) facilitó el paso de monarquía a nación como cuerpo colectivo ${ }^{91}$.

La Voluntad General rousseauniana la encontramos filtrada a través del sentimiento religioso de fraternidad y de búsqueda del bien común: así Oliveros atribuye a la primera iglesia hispana un papel en el reconocimiento de derechos políticos a la Nación: «El tiempo y las luces de los ministros evangélicos suavizaron las costumbres de los godos, y acaso hubieran llegado á su perfección si la irrupción de los moros no hubiera confundido todas las cosas (...) Si existen leyes contradictorias, éstas son fruto de la actitud vacilante de los reyes y no de la nación que siempre busca el bien general» ${ }^{92}$.

La inviolabilidad del Rey la relaciona Villanueva con el restablecimiento de la unción real: «Hago proposición de que se restablezca la ceremonia antiquísima en España de ungir al Rey al tiempo de su coronación. Notorio es que este rito se instituyó por toda la Nación de la Monarquía goda en los tiempos en que el pueblo comenzó a ser admitido a la sanción de las leyes, no para denotar en el Rey potestad alguna espiritual, ni para imprimir carácter en su alma, como sucede en las consagraciones propias de las personas eclesiásticas, sino para denotar la elevación de su autoridad, que le constituye superior a todo juicio humano, y responsable a solo Dios del uso de su poder, que es lo que denotan en la Constitución las expresiones inviolables y no sujeto a responsabilidad (...) Que esta ceremonia hubiese sido grata a la Nación española, lo demuestra el ansia con que la adoptaron después los reinos de León y de Castilla en la época en que gozaba el pueblo de los derechos de su libertad ${ }^{93}$. Considera que España fue, antes que

\footnotetext{
88 Llamas, DSC, 28/8/1811, no 330, 1714.

89 Alcocer, DSC, 28/8/1811, no 330, 1713-1714.

90 Villagómez, DSC, 7/6/1811, no 249, 1202-1203.

91 PORTILLO, «De la monarquía católica», 31.

92 Oliveros, DSC, 10/6/1811, no 252, 1232-1235.

93 Villanueva, DSC, 9/10/1811, no 372, 2024.
} 
Francia, quien instituyó esta ceremonia (considerando fabulosa la unción de Clodoveo a manos de San Remigio). Ante las dudas de Argüelles del porqué fue eliminada y de su carácter religioso más que político, Villanueva considera que fue eliminada para evitar que se entendiese que los reyes lo eran por gracia y delegación del Papa (cuando en realidad eran celosos del verdadero origen de su autoridad $^{94}$. La Comisión que estudió esta posibilidad de la unción ${ }^{95}$, decidió rechazarla porque pudo ser útil en una monarquía electiva («en la que era oportuno dar un carácter exterior que conciliase más el respeto del pueblo hacia una persona que no le había podido inspirar anteriormente»), pero no lo era en una hereditaria. No se pone en duda el carácter confesional de la nación.

Esta concepción simbiótica de Soberanía condiciona la relación Rey-Pueblo. Esta relación se basa en un pacto con un fuerte componente moral y de amor: «(los) Españoles que aspiran imitar a sus abuelos, a aquellos insignes varones que acaso los primeros en Europa supieron decir a sus Monarcas, Nos que somos mas que vos...Los Españoles del año de 1813 difieren esencialmente de los que en el año de 1800 sufrían los golpes del despotismo por respeto a la majestad: conocen sus derechos; conocen su poder, y saben que nuestras leyes no fundan la sumisión sobre la naturaleza semidivina que nuestro político atribuye a los Reyes, sino sobre el amor y la honra que estos dispensaron a sus súbditos» ${ }^{96}$. El espíritu público se degrada cuando no existe amor del pueblo a su rey y viceversa: «El esplendor y el poder de la nación crecieron mientras que el Rey y el pueblo formaron una familia, unida por los lazos del amor (...) Por el contrario: desde que olvidados nuestros reyes de sus obligaciones trataron a la Nación como a un rebaño condenado al degüello; y despreciando el amor del Pueblo (...) desapareció el espíritu público, causador en otras épocas de hazañas: se degradó el carácter español» ${ }^{97}$. En este mismo sentido se expresa García Herreros para explicar el origen de los señoríos: «Roto el lazo moral, que es la ley, ya no hubo unión entre pueblo y príncipe; se desquició la sociedad española» ${ }^{98}$. Este pacto moral es tan importante como el legal: así Luján, refiriéndose al incumplimiento de los pactos por parte de los reyes, «Los Reyes están obligados a guardar lo que ofrecen en sus tratos particulares, porque obran por sí; pero cuando se entrometen en lo que no les toca, cuando no pueden formalizar aquellos pactos, cuando ellos mismos han ju-

94 Ibidem, 2025.

95 Comisión, DSC, 1/11/1811, nº 395, 2194.

96 «Política: Reflexiones», TPE, 23/3/1813, no 42, 255.

97 «Política: Nada es mas funesto para un Estado que el carecer su gobierno de la opinión pública» en ETPE, 2/2/1813, no 27, 5 .

98 García Herreros, DSC, 4/6/1811, no 246, 1176. 
rado no hacerlos, cuando las leyes del Rey no lo prohíben, cuando estos pactos son contra la naturaleza y fin de la misma sociedad y de la Monarquía, no hay tales pactos, nada valen, y nunca producen ni acción ni obligación, no digo civil para poder reclamar su observancia, sino ni natural, ni aun de decencia, para el efecto ${ }^{99}$.

En algunos casos, esta ruptura del lazo se consiguió restablecer en el momento de la muerte del monarca, momento decisivo en la vida de cualquier persona, «En aquellos terribles momentos para los hombres religiosos, desaparecen las falsas razones de la sofistería, y aparece solo la verdad y la justicia» ${ }^{100}$. Decisiones contrarias al bien del pueblo, como en el caso de las enajenaciones, se corrigieron en estos momentos: «que apenas hubo Rey de Aragón o de Castilla que, al tiempo de morir, no se arrepintiese de haber enajenado bienes de la Corona; algunos, como por ejemplo, la Reina Doña Isabel y Felipe III, dejaron declarado que habían procedido en ello contra su voluntad, y todos clamaron porque volviesen estos bienes al Real Patrimonio» ${ }^{101}$.

Pero así mismo, este tipo de soberanía condiciona el tipo de monarquía resultante: «La monarquía templada presenta un aspecto el más brillante. El honor, las virtudes públicas, el respetuoso atrevimiento con que se oponen los representantes de la nación a las voluntades injustas del soberano, la necesidad de recurrir a éste para las gracias y empleos, y la necesidad de merecerlos para no atraerse la indignación pública, producen el amor general a los talentos útiles, a los verdaderos patriotas, a las virtudes domésticas, sin las cuales no hay virtudes civiles ${ }^{102}$.

\section{CONCLUSIÓN}

Frente a la acusación de volatilidad ideológica, son cada vez más frecuentes los trabajos, centrados en algún publicista concreto, que tienden a mostrar una mayor coherencia y, sobre todo, una mayor profundidad en el pensamiento de estos políticos. En los últimos años se ha intentado valorar conjuntamente con las ideas políticas, las creencias religiosas de estos autores. En el presente trabajo hemos pretendido mostrar el esfuerzo de simbiosis realizado por numerosos libe-

99 Luján, DSC, 5/6/1811, no 247, pp. 1188-1189.

100 Oliveros, DSC, 10/6/1811, no 252, 1234.

101 Villanueva, DSC, 4/6/1811, no 246, 1179-1181; también Caneja, 8/6/1811, n 250, 1210-1211.

102 «Del espíritu público de las naciones», EES, 21/10/1809, nº 20, 78. 
rales para adaptar los nuevos conceptos políticos con los principios católicos desde una perspectiva totalmente diferente de la adoptada por los elementos más conservadores. De igual modo, y desde una perspectiva liberal, esta simbiosis no da un resultado único y uniforme; y así tenemos las dos tendencias que representarían F. Martínez Marina y A. Lista. El resultado puede parecer un híbrido aparentemente ecléctico, con características del jansenismo, iusnaturalismo, principios de Locke, Montesquieu o Rousseau. En nuestra opinión, el resultado obtenido solo puede ser correctamente analizado si nos abstraemos de las clásicas valoraciones del pensamiento político y utilizamos unos amplios campos semánticos que incluyan factores que valoren las creencias. Debemos afrontar que los nuevos conceptos políticos de la era de las revoluciones, estuvieron marcados en el mundo hispano, internamente y estructuralmente por la raíz católica presente en la sociedad, aportando una solución, diferente en algunos aspectos, a la que se dio en otros países como por ejemplo Francia. Adoptando esta postura es posible que lleguemos a valorar la Constitución de Cádiz y todo el proceso constituyente, en lo que fue y no en lo que nos hubiera gustado que fuese.

Title:

RELIGIOUS SENTIMENTS AND ETHICS IN THE POLITICAL CONCEPS OF FIRST SPANISH LIBERALISM

\section{Summary:}

1. Introduction. 2. Ethics and Religion. 3. Parlamentary and journalistic debates. 4. Influences on the political terms meanings. 5. Conclusion

\section{Resumen:}

Desde una perspectiva doctrinal de la historia del constitucionalismo, pretendemos destacar los diferentes significados de los conceptos políticos clave manejados por parte del mundo liberal durante los debates parlamentarios que dieron lugar a la Constitución de Cádiz. En el curso de los debates gaditanos hay continuas alusiones por parte de los representantes de cualquier tendencia ideológica, a la virtud, a la moral, a los derechos naturales; en el caso de los liberales vinculándolos con los nuevos conceptos políticos o los nuevos significados de los mismos, en el caso de los tradicionales, vinculándolos con los antiguos significados. El presente trabajo pretende destacar en los discursos parlamentarios y periodísticos las referencias a la virtud, a la moral, a los derechos naturales y cómo la defensa de los mismos condicionó el significado atribuido por los 
políticos a los conceptos manejados. Sin querer marcar un particularismo hispano, pretendemos reivindicar la creación, por parte del mundo liberal, de un pensamiento más complejo, elaborado y sobre todo coherente en el tiempo, de lo que se ha considerado hasta ahora, donde las creencias religiosas juegan un papel estructural, así pues, fundamental para entender el significado de los conceptos políticos manejados.

\begin{abstract}
:
The doctrinal perspective of the Constitutional History is here used in order to explain the different meanings of the «key» political concepts used by liberal politicians in the debates on the constitutional draft which eventually produced the Cadiz Constitution. In the parliamentary debates the politicians of whatever ideologies do continuous references to values as the virtue, the ethics, the natural rights, ... Liberal politicians relate those values with the new political concepts or with their new political meanings while traditional politicians relate them with the old meanings. By analyzing the political discourses related to the Cadiz Constitution, this paper tries to evidentiate the role played by the defence of the virtue, the ethics and the natural rights and how that defence determined the meanings of the political concepts. Even if the Spanish case is not specific, the paper outlines that the liberal politicians, contrarily to the opinion currently accepted, created a complex and coherent thought in which the religious believes play a role not only structural but also fundamental for understanding the meanings of the used political concepts.
\end{abstract}

\title{
Palabras clave:
}

Constitución de Cádiz, Historia Conceptual, Moral, Religión.

Key words:

Cadiz Constitution, Conceptual History, Ethics, Religion 
